FACTA UNIVERSITATIS

Series: Physical Education and Sport, Vol. 16, No 2, 2018, pp. 229 - 244

https://doi.org/10.22190/FUPES170314021P

Research article

\title{
THE OPTIMAL KINEMATIC MODEL OF THE PERFORMANCE OF THE CLEAR HIP CIRCLE TO HANDSTAND ON THE UNEVEN BARS - A CASE STUDY
}

\author{
UDC 796.414.5:531.1
}

\author{
Emilija Petkovic $^{1}$, Saša Veličković ${ }^{1}$, \\ Edvard Kolar ${ }^{2}$, Ratko Stanković ${ }^{1}$, Daniel Stanković ${ }^{1}$ \\ ${ }^{1}$ Faculty of Sport and Physical Education, University of Niš, Niš, Serbia \\ ${ }^{2}$ Olympic Committee, Ljubljana, Slovenia
}

\begin{abstract}
The aim of this research was to define the optimal kinematic parameters of performance of the Clear hip circle to handstand on uneven bars (KOVT). The optimal kinematic model defined in this case study represents an example of the successful performance of the Clear hip circle to handstand on the uneven bars. The exercise was performed at the $39^{\text {th }}$ and $40^{\text {th }}$ World Cup in Artistic gymnastics in Maribor (SLO). The kinematic parameters were specified by the APAS 3-D video system (Ariel Dynamics Inc., San Diego, CA), using 16 anthropometric reference points and 8 body segments (Foot, Ankle, Knee joint, Hip joint, Wrist, Elbow joint, Shoulder joint and Head), in which one of the points represents the center of gravity of the body. The female gymnasts $(N=15)$, mean age 17.5 yrs, who performed one Clear hip circle on the uneven bars performed two KOVTs in their gymnastics routine, while the rest performed one KOVT on the uneven bars, mean age 17.5. The main method in this research was kinematic, and the additional one was statistical. Optimizing the technique of successful performance of the KOVT is important for detecting different styles of the technique that occur in female gymnasts.
\end{abstract}

Key words: female gymnasts, kinematics, uneven bars, technique analysis

Received March 14, 2017 / Accepted September 10, 2018

Corresponding author: Emilija Petković

University of Niš, Faculty of Sport and Physical Education, Čarnojevića 10a, 18000 Niš, Serbia

Phone: +381 $18510900 \bullet$ E-mail: emilija@fsfv.ni.ac.rs 


\section{INTRODUCTION}

Uneven bars are one of four apparatus in women's gymnastics where continuous swinging and giant movements are predominant. Exercises are the smallest movement structures, interconnected with a competitive combination of compositions which gymnasts present to the judges during competitions. Judges define errors in movement and evaluate exercises based on subjective observations and prescribed rules. Model assessment which is provided by the Code of Points refers to an implementation model performance in gymnastics. Any deviation from this model means breaking a rule that is sanctioned with the loss of a certain number of points for a mistake that can be aesthetic or technical in nature. The kinematic analysis of a certain kind of movement is becoming more and more frequent in artistic gymnastics; particularly as the obtained information enables a more rational and economical instruction of the analyzed movement (Brueggemann, Cheetham, Alp, \& Arampatzis, 1994; Takei, \& Dunn,1996; Kolar, Andlovic - Kolar, \& Štuhec, 2002; Tsuchiya, Murata, \& Fukunaga, 2004). When it comes to the uneven bars, it should be noted that it is necessary to fully explore the techniques, primarily, of the basic movement. Movement on the bars is predominantly executed using two planes; movement in the sagittal plane such as the giant swing where the axis is the horizontal bar, and turning movements that occur in the transverse plane where the axis extends through the centre of the gymnast's body from the top of the head through to their feet (Pidcoe et al., 2011). The Clear hip circle to handstand is a basic movement pattern in gymnastics. The Clear hip circle to handstand on uneven bars was classified in the Code of Points (2005-2008) as a group of exercises with a "B" value, with circular movements as a "specific request" that the structure of the composition of the gymnast's performance requires.

A few research papers have offered a kinematic analysis on the uneven bars. Alekperov (1987) analyzed the performance technique and came to the conclusion that kinematic parameters allow overleaps to the bar with bent hands, but today this represents a mistake in performing this exercise. To overleap the bar, Alekperov believes that the height of the center of gravity of the body (TT) at the moment of the reach should be at $100 \mathrm{~cm}$, which requires initial flight speed of $4 \mathrm{~m} / \mathrm{s}$. Prassas (1994) studied the dynamics of forward swing skills and the back toss on the parallel bars. Also George (1980) set the ideal model of clear hip circle to handstand on the uneven bars and later at the World Championship in 1979 carried it out in practice. The ideal model provides a 3-phase technique, but the application model confirms the 3-phases of the technique with different kinematic parameters (Petković, Veličković \& Stanković, 2006) with 2-D video system analysis. Prassas (2002) systematized all the biomechanical studies that have been carried out in Men's and Women's Artistic gymnastics. Veličković (2005) investigated the difference between good and bad execution of the Basket to Handstand on the Parallel bars. The participant in the study was the European and world champion on the Horizontal bar, the Slovenian Mitja Petkovšek. A kinematic analysis enabled the identification of four clearly defined stages in the movement: 1) the Upswing from a handstand, 2) Decline in back to ascend higher, 3) in Front ascend higher, 4) Decline to a handstand. The studies of Veličković, Kolar, \& Petković (2006); Veličković et al. (2005), Veličković, Kolar, \& Petković (2006) have confirmed the 4-phase structure of this exercise on the Parallel bars. Hiley (2012) said that optimisation criteria must reflect the performance outcome rather than the amount of effort required. When optimising technique, minimising effort or joint 
torque is often used as the basis of the score (or cost function). The increase of the objectification level ranges from pedagogical criteria to biomechanical ones. That is why the biomechanical criteria are used for dividing the gymnastics elements into parts. The technical structure of gymnastics elements contains three levels - periods, stages and phases (Suchilin, 2010, 5).

The aim of this research was to define the kinematic parameters of the clear hip circle to Handstand on the uneven bars. The exercise was performed at the $39^{\text {th }}$ and $40^{\text {th }}$ World Cup in Artistic gymnastics in Maribor (SLO). The research has defined the kinematic parameters of the optimal model of fifteen female finalists of the $39^{\text {th }}$ and $40^{\text {th }}$ World Cup in Artistic gymnastics in Maribor (SLO). The kinematic model of the performance of the clear hip circle to handstand on the uneven bars is a case study with the optimal definition of the kinematic parameters of fifteen female gymnasts. The optimal kinematic model defined in this case study represents an example of the successful performance of the clear hip circle to Handstand on the uneven bars.

\section{METHODS}

This study has a kinematic character and it included data recorded in competitions on the World Cup Series on the uneven bars in Maribor (SLO). The main method in this research was kinematic and the additional was statistical. The kinematic method determined the mean value of the trajectory and speed of movement of the referent points during the execution of KOVT. The statistical method included a multivariate analysis intercorrelation matrix of the trajectory of the foot. The research method is a set of procedures used to achieve the objective of defining a kinematic model of the basic techniques of performing gymnastic exercises on the uneven bars. The research sample consists of 19 female gymnasts who participated in the $39^{\text {th }}$ and $40^{\text {th }}$ World Cup in Maribor, and in the Final performed 15 clear hip circles to Handstand on the uneven bars (KOVT). In this study we analyzed only the kinematic parameters of gymnasts who performed a clear hip circle to Handstand on the uneven bars (KOVT) in the Finals. At the $39^{\text {th }}$ World Cup, 7 gymnasts participated in the Final competition on the uneven bars. Only 5 gymnasts performed the clear hip circle to handstand on the uneven bars in their gymnastic routine. Gymnasts who performed one clear hip circle on the uneven bars at the $39^{\text {th }}$ Word Cup in Maribor were: Mayer (AUT), Erceg (CRO), Gombas (HUN), Pechancova (CZE), Paulickova (SVK). All gymnasts performed one KOVT in their gymnastic routine on the uneven bars ( $\mathrm{n}=5$, female, born in 1988-1990, mean age: $17 \pm 6$ months). At the $40^{\text {th }}$ World Cup 8 gymnast participated on the uneven bars, but 10 clear hip circles to Handstand have been performed on the uneven bars. Gymnasts who performed one clear hip circle on the uneven bars at the $40^{\text {th }}$ Word Cup in Maribor were: Han (CHN), Briand (FRA), Roberts (GBR), Millousi (GRE), Delladio (CRO), Tijmes (NED), Golob (SLO), Urvikko (FIN). Gymnasts Han (CHN) and Urvikko (FIN) performed two KOVT in their gymnastics routine and the rest performed KOVT on uneven bars ( $\mathrm{n}=8$, female, born in 1988-1991, mean age: $17.5 \pm 6$ months). The sample of measuring instruments that we used consisted of a set of kinematic parameters which are calculated on the basis of the 8-segment anthropometric model (Foot, Ankle, Knee joint, Hip joint, Wrist, Elbow joint, Shoulder joint and Head -EXT). The center of gravity (CG) 
of the body (TT) was calculated based on the model presented by Winer (1991). Our analysis only took into account the points and segments of the right side of the body, because the speed of the body was the same and for the analyzed exercise, and priority had been given the side that was closer to the camera objectives.

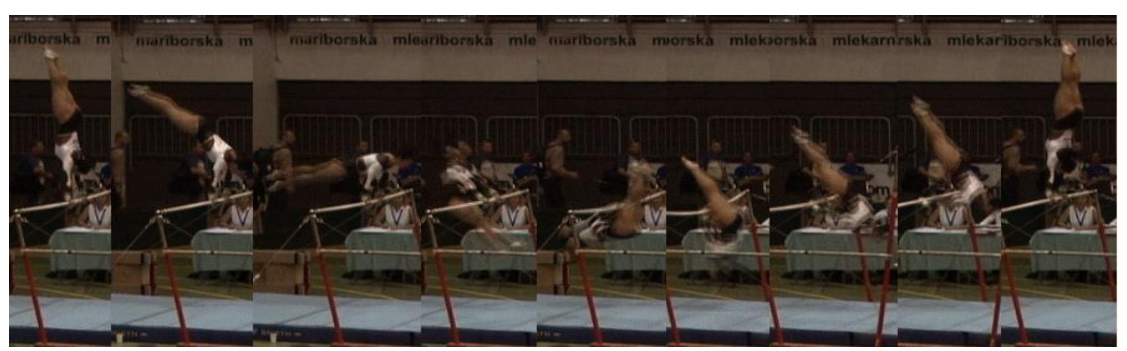

Fig. 1 Clear hip circle to Handstand on the uneven bars - KOVT, performed by Mayer, S.

The Ethics Committee of the Faculty of Sport, University of Ljubljana approved all experimental procedures according to the revised Declaration of Helsinki. Data processing was carried out according to the standards of the Ariel Performance 3D Video System (APAS) used for kinematic analysis, which included 16 reference points conducted through several phases: frame grabbing, digitalization of the recorded videos and the reference points of the body, transforming the three-dimensional space, data filtering and the calculation of kinematic quantities. Gymnastics routines on the uneven bars were recorded by two digital cameras DVCAM SONY DSR - 300pk that were located to the left and right sides' reconciliation at a right angle $\left(90^{\circ}\right)$ relative to the axis that is normal to the direction of movement of the gymnasts and which passes through the middle of this apparatus (between the lower and higher bars) and rotation axis. The frequency of the camera was $50 \mathrm{~Hz}$. The cameras were synchronized to each other's internal synchronous system. All of the movements were performed in the same direction. As the element performed on the uneven bars had the characteristics of a $2 \mathrm{D}$ movement, there was no significant movement along the mediolateral (z) axis.

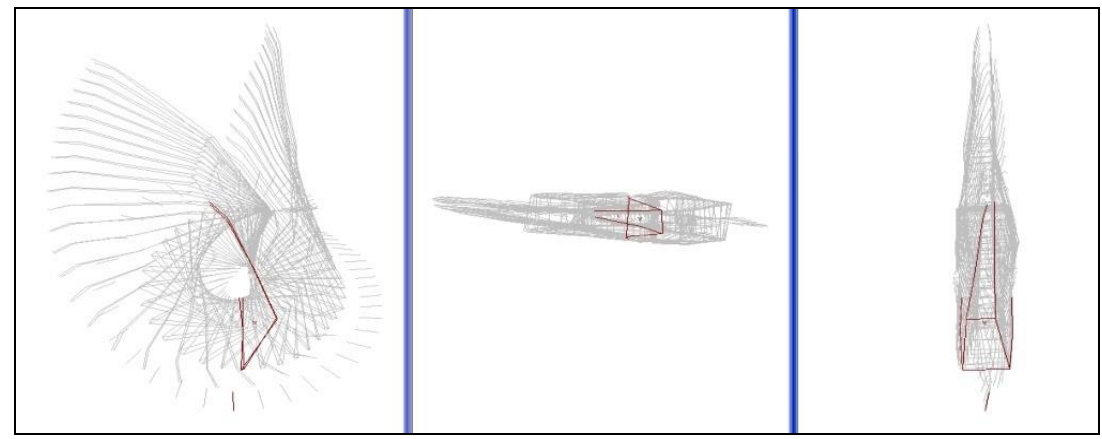

Fig. 2 A visual representation of the 3D kinematic modeling of the clear hip circle to Handstand 
Before the recording during the competition, in order to define the field of measurement and to take precise calibration of space, there were tree frames of reference $(2 \times 1 \mathrm{~m} 3)$ leveled on the bars. Since the exercise was performed on the uneven bars, and the gymnasts performed on the lower and upper Bars, on the right or left side of the Bars, it was necessary that the different starting positions of the competitors be brought to the same level, i.e. the same starting position, so that a moderate space could be processed by the APAS program. The moderate space required that everything should be altered so that the first gymnast could represent an absolute space. The exercise performed by Mayer, S. (AUT) at the $39^{\text {th }}$ World Cup was the basis for the absolute zero height and length for all other performed clear hip circles to Handstands on the uneven bars - the exercises performed by other gymnasts were moved into this absolute space. All of the performed exercises were moved so that the center area was in the axis of rotation.

\section{RESULTS}

Significant positions in the performance of the clear hip circle to the Handstand were established by the Institute of the Faculty of Sport in Ljubljana. The performed exercise which was selected for analysis takes up 1, 1 seconds and were allocated for every movement of 52 positions in the performance. Analyzing the trajectories of the selected 8 anthropometric points, 4 significant positions were determined, designated by the 4 stages in the technique of movement. The results of this research contributed to the definition of the theoretical model, which requires four phases (Fig. 3): I Control gravity phase Upswing from a handstand position to balance the resistance front (position 1-16); II Gravitational phase - Downswing to upswing with clear support (17-36); III Lower vertical passing (37-46); IV Swing to Handstand position (47-52).

Phase I - Control gravity phase - Upswing from a handstand position to balance the resistance front. Phase II - Gravitational phase begins when the starting point of the shoulders moves back from the position of the balance and lasts until the point of the shoulder pass below the vertical line (position of the front pike hang). The gymnast ends this phase in the 36th position when the body begins the circular movement i.e. the eccentric decline (Popov, 1986). The aim of the movement at this stage is to accumulate large amounts of kinetic energy and this phase is called the accumulation phase (Smolevski, in Petković, 2009). Phase III - Lower vertical passing begins by passing through the lower point of the shoulder vertical and lasts until the moment of relief from the bar and stretching the shoulder joint and hip. The gymnast completes this stage at the $46^{\text {th }}$ position. This phase is characterized by a negative effect of gravity, which gradually slows down the movement (antigravity direction). After passing the verticals, the angle of the shoulder joints starts to increase. In the position when the shoulder is approximately at the level of the bar and the feet are above the head, moving the feet - the caudal part of the body is interrupted, creating a position to actively transfer momentum from the legs to the torso allowing a suitable condition for the extensors in the shoulder joint. Performance in this phase is easier because of the elastic properties of the Bars. When moving in a gravitational direction, the central part of the grip moves in the downward direction, while moving in the anti-gravitational direction returns it to the original position. Phase IV - Swing to Handstand position - when the benefits of all the accumulated energy in order to perform certain movements of the 
support phase are achieved. Stretching the body ends with the re-grasp of the bar, after which the body is short and apparently stops and then continues to move by inertia.

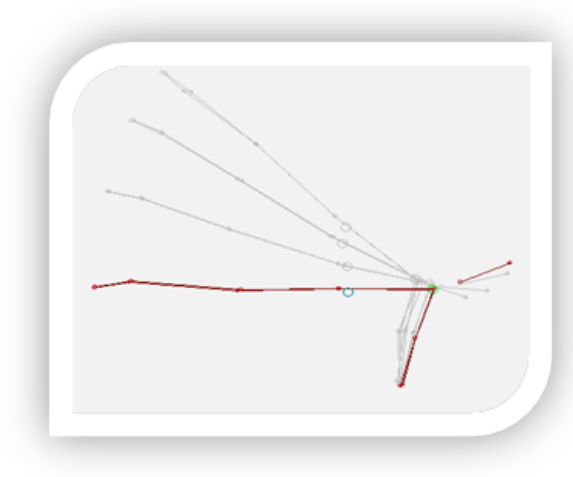

I. Control gravity phase (16 position)

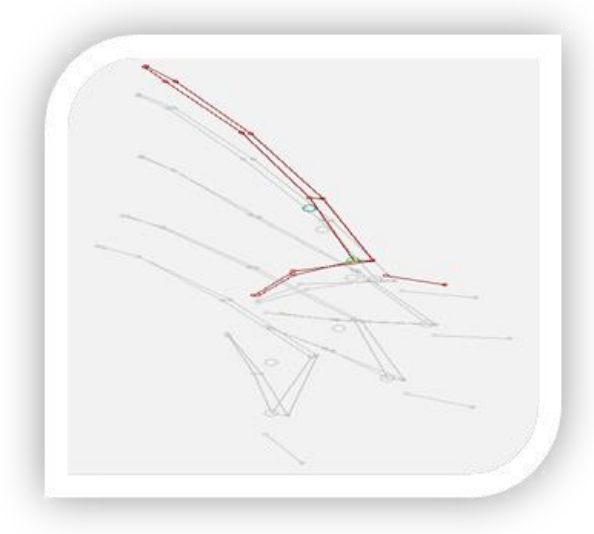

III. Lower vertical passing (46 position)

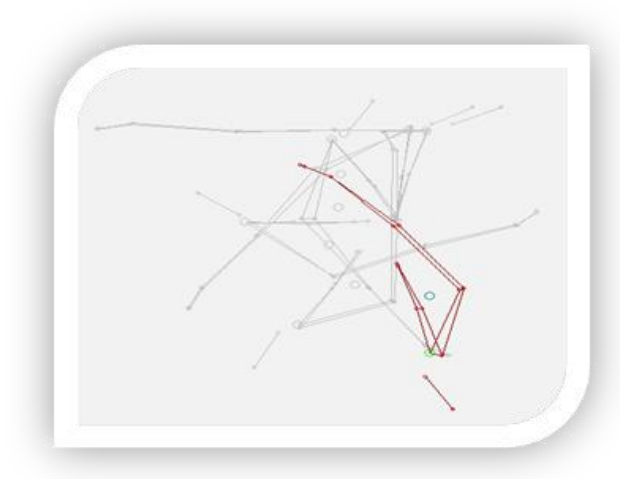

II. Gravitational phase (36 position)

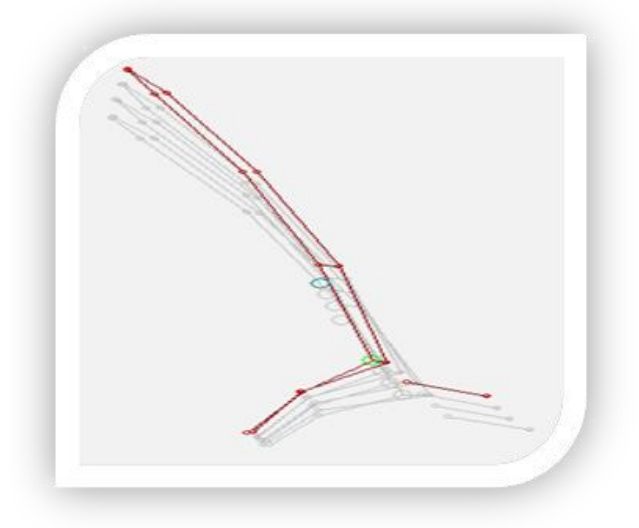

IV. Swing to Handst. position (52 position)

Fig. 3 Significant positions in the performance for kinematic modeling (B. Han)

\section{DISCUSSION}

The optimal kinematic model defined in this case study represents an example of the successful performance of the clear hip circle to Handstand on the uneven bars. "Biomechanical research in artistic gymnastics can be performed using both biomechanical methods and methods taken from other fields of knowledge (pedagogical, mechanical, physiological, psychological, medical ones, etc.), mainly intended to highlight the features of movement on various apparatus by selecting the means of data recording, processing and analysis" (Potop, 2014).

The results of this research contributed to the definition of the theoretical model, which requires four phases. The clear circle technique was predicted by minimising peak joint torque at the shoulder and hip using a simulation model (Hiley \& Yeadon, 2013). 
Phase I - Control gravity phase begins from a handstand position and ends at the moment of reaching the position of the balanced handstand, when the shoulder deviation reaches the maximum position forward (in the $16^{\text {th }}$ position when the axis of the shoulder joint forms an angle with the center of the support grasp). The handstand position on the uneven bars is an unstable type of balance, considering the fact that two fundamental forces, the resultant force vector of the muscles and the force of gravity, are taken out of the previous equilibrium effects. The characteristic of the upswing is that after the movement, two pendulum systems are created (Veličković et al., 2011) - the hanging pendulum and the supported pendulum. The first system that controls the body and legs while 'falling down' by rotating around the axis that is drawn through the center of the shoulder joint. In this system the position of the foot moves backwards, decreasing the angle between the torso and the legs. Another system that is made up of the arms and shoulders moves forward and the motion slows down.

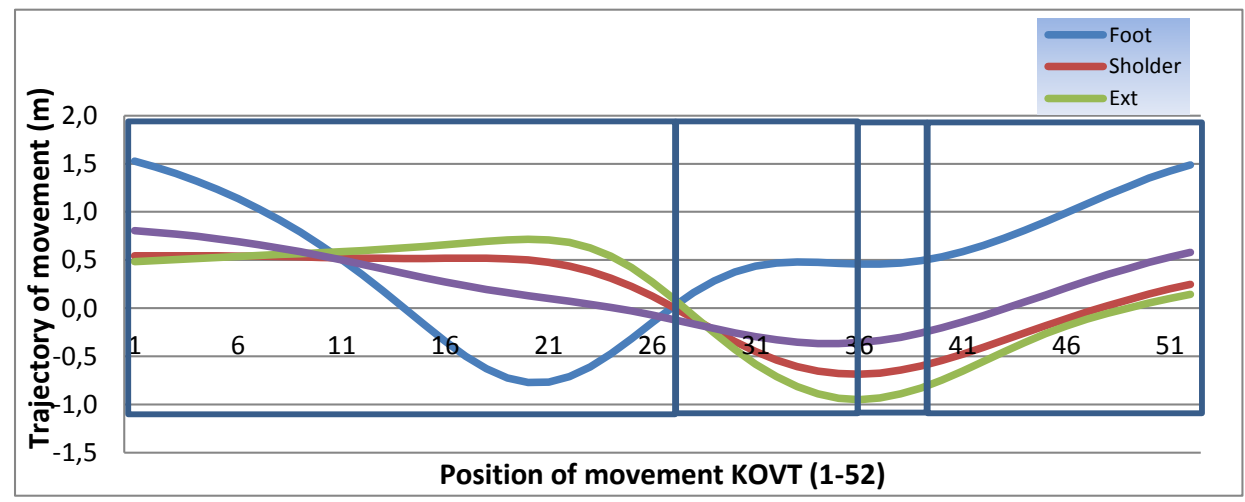

Fig. 4 Movement trajectory of the referent points from the y-axis for KOVT; Ext - Head, CG - center of gravity

Since the beginning of the movement until the end of Phase I, the trajectory point of the shoulder and the vertices is strictly horizontal (no change in the value of the y-axis). The focus of the body gradually descends downwards (only the vertical trajectory - already shown in the analysis of the trajectory on the $\mathrm{x}$-axis). The tops of the feet also reduce the value of the trajectory along the y-axis or significantly steeper trajectory. The match trajectories point of the shoulder, foot and center of gravity comes into a position where the shoulder ends its movement forward (the mean of the matching trajectory is in the $10^{\text {th }}$ position with a value of $0.500 \mathrm{~m}$ ), the position of the body is as in Figure 4 . The zero position represent the axis of rotation (Bar) around which the KOVT movement is performed. The trajectory of movement represent a path during the execution of KOVT. Values have been marked in meters and positive and negative values from the zero position represent the movement of the examined points to the right or left side of the bar. Positions 10 and 28 are performing places where the trajectories intercross the investigated points, which means that these are positions that are necessary where the parameters have to pass in addition to performing a successful technique. 


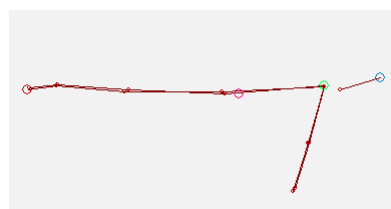

a) Han, 10 position

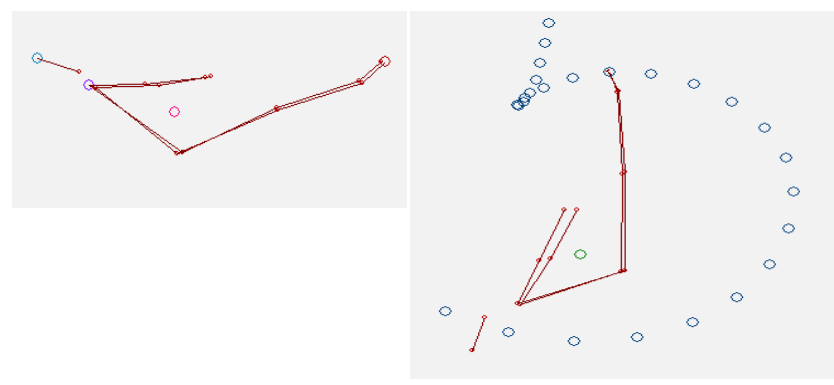

d) Han, 25 position

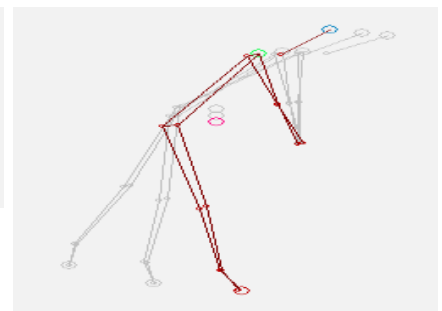

b) Han, 16-18 position

e) Han, 30 position

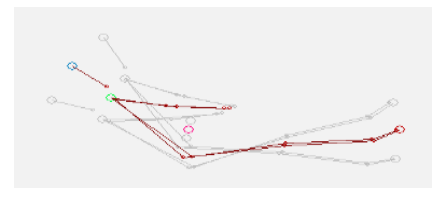

c) Han, 23-25 position

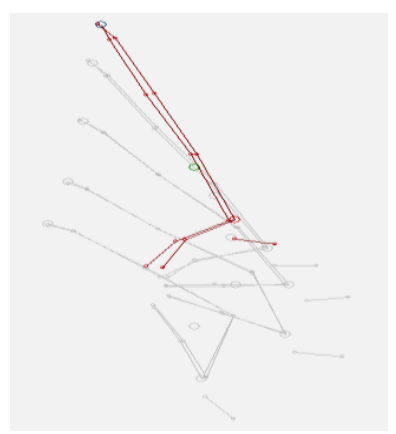

f) Han, III-IV Phase

Fig. 5 The most important position in the performance of the clear hip circle to Handstand on the Unbars

Entering Phase II of the movement trajectory keeps the same tendency to the point position when the shoulder comes out from the surface of the support (values begin to decrease - a positive sign - Fig 5b), the foot reaches the minimum value of the trajectory (firs position = $0.479 \mathrm{~m}$ to the position $21=-0.753 \mathrm{~m}$ ), followed by moving their magnification (negative sign, Fig 5c). The crossing points of the trajectory of the shoulders and tops of the feet with the successful developments are realized in the period of movement when the value of the y-axis is very close to zero with one hand and with the other observed point. If this crossing occurred in some other values on the y-axis (significantly different from zero), the system would probably not be able to keep the central movement (Fig 5d). In real terms this crossing is formed in the $27^{\text {th }}$ position with average values of the trajectory from $-0.023 \mathrm{~m}$ to $0.030 \mathrm{~m}$. After crossing two points, the value of the trajectory of the foot increases and has positive values (Figure 5e), and the value of the other three points is reduced to negative values (position 27). This trend continues to the position where the feet are approximately vertical and the trajectory of the center of the lower vertical cuts in the $35^{\text {th }}$ position with $\mathrm{s}=-0.362 \mathrm{~m}$ ( $\mathrm{s}$ - distance traveled, shown in meters). By the end of Phase II the values of the trajectory gravities of the body, shoulders and crown of the head are reduced to a minimum value at the $36^{\text {th }}$ position $\left(\mathrm{s}_{\mathrm{CG}}=\right.$ $\left.0.353 \mathrm{~m}, \mathrm{~s}_{\mathrm{SH}} 36=-0.672 \mathrm{~m}, \mathrm{~s}_{\mathrm{EXT}}=-0.928 \mathrm{~m}\right)$, while the feet start lowering the value of the same parameter as in Fig $5 \mathrm{e}\left(\mathrm{s}_{\text {Foot }}=0.461 \mathrm{~m}\right)$.

In Figure 5f, it can be seen that phase III is formed between the $37^{\text {th }}$ and $46^{\text {th }}$ position. In the Phase III the body of the gymnast must be extended in all the joints to be able to act according to the biomechanical principle of the transfer of momentum from the open part of the kinetic chain (leg) on the closed section (trunk), which is the continuation of the movement taking 
place, against the gravitational force that tends to return the body down. At this stage, all the points start a translational movement on the $y$-axis upwards. Figure $5 f$ shows the trajectory of reference points and all the points when starting a translational movement on the y-axis upwards (from the start of phase III they are directed upwards), or in stage IV travel up due to the transfer momentum to a closed part of the kinetic chain. The movement may be stopped due to insufficient stretching in all the joints and contractions in certain joints (the hip or elbow).

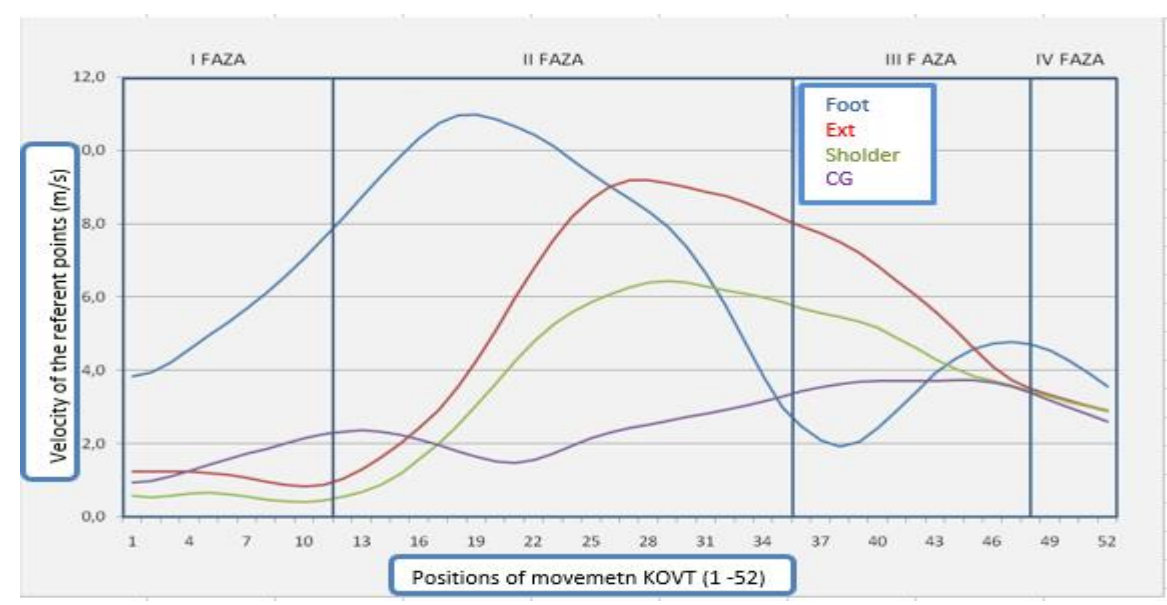

Fig. 6 Velocity of referent points in the xy-plane for KOVT; $\mathrm{CG}$ - center of gravity, Ext - Head

Figure 6 presents the velocity of the referent points in the xy-plane for KOVT. From the Figure it can be seen that during phase I the speed and velocity of the foot and center of gravity are increasing. The maximal value of the foot velocity is reaching at position 17 $\left(\mathrm{V}_{\text {foo }} \mathrm{t}=11.6 \mathrm{~m} / \mathrm{s}\right)$. By the end of phase I the speed velocity of the center of gravity reaches its maximal value $\left(\mathrm{V}_{\mathrm{CG}}=2.4 \mathrm{~m} / \mathrm{s}\right)$. Velocity of the foot decreases from position 17 up to position 38 , when it increases again but not as much. Velocity of the center of gravity is moving slower up to position 22 when it increases up till the end of phase III. Another system that is made up of the arms and shoulders and CG moves forward and the motion slows down, reaching minimal values at position 12 (Fig 11). At phase II the velocity of referent points of the shoulder $\left(\mathrm{V}_{\mathrm{SHOLDER}}=6,3 \mathrm{~m} / \mathrm{s}\right)$ and head $\left(\mathrm{V}_{\mathrm{EXT}}=9,2 \mathrm{~m} / \mathrm{s}\right)$ reach maximum speed and then they decrease up to the end of movement.

The statistical method included a multivariate analysis - intercorrelation matrix of the trajectory of the foot along the y-axis for KOVT. Table 1 presents the intercorrelations of the trajectory of the foot along the y-axis for gymnasts who performed the clear hip circle to Handstand on the uneven bars on the $39^{\text {th }}$ and $40^{\text {th }}$ Word Cup in Maribor (SLO). 
Table 1 Intercorrelation of the trajectory of the foot along the y-axis for KOVT

\begin{tabular}{|c|c|c|c|c|c|c|c|c|c|c|c|c|c|c|c|}
\hline & $\sum_{\bar{\Sigma}}^{\grave{\Xi}}$ & $\begin{array}{l}\underbrace{0}_{0} \\
\text { 章 }\end{array}$ & 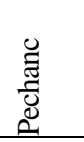 & $\begin{array}{l}\text { है } \\
\text { ह్ँ } \\
\tilde{0}\end{array}$ & 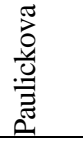 & $\bar{\Xi}$ & $\begin{array}{l}\text { N } \\
\text { I } \\
\end{array}$ & 胥 & $\begin{array}{l}0 \\
\frac{0}{0} \\
\stackrel{0}{0} \\
\simeq\end{array}$ & $\begin{array}{l}\overline{\underline{z}} \\
\overline{0} \\
\bar{\Sigma}\end{array}$ & 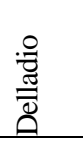 & $\underset{\Xi}{\stackrel{\mathscr{\Xi}}{\Xi}}$ & $\begin{array}{l}\frac{0}{8} \\
0\end{array}$ & $\begin{array}{l}0 \\
\frac{8}{5} \\
5 \\
\end{array}$ & $\begin{array}{l}2 \\
0 \\
0 \\
2 \\
5 \\
\end{array}$ \\
\hline Mayer & 1,000 & & & & & & & & & & & & & & \\
\hline Erceg &, $981^{* * *}$ & 1,000 & & & & & & & & & & & & & \\
\hline Pechancova &, $915^{* * *}$ &, $916^{* *}$ & 1,000 & & & & & & & & & & & & \\
\hline Gombas & ,981** &, $956^{* *}$ &, $836^{* *}$ & 1,000 & & & & & & & & & & & \\
\hline Paulickova &, $995^{* * *}$ & $987^{* *}$ &, $932^{* *}$ &, $974^{* *}$ & 1,000 & & & & & & & & & & \\
\hline Han 1 &, $948^{* * *}$ &, $933^{* *}$ &, $778^{* *}$ &, $988^{* *}$ &, $945^{* * k}$ & 1,000 & & & & & & & & & \\
\hline Han 2 &, $975^{* * *}$ &, $966^{* *}$ &, $842^{* *}$ &, $995^{* *}$ &, $975^{* * k}$ &, $991^{* *}$ & 1,000 & & & & & & & & \\
\hline Briand &, $994^{* *}$ &, $988^{* * *}$ &, $887^{* *}$ &, $987^{* *}$ & $990^{* * *}$ &, $966^{* *}$ & ,987 & 1,000 & & & & & & & \\
\hline Roberts &, $955^{* *}$ &, $940^{* * *}$ &, $801^{* *}$ &, $990^{* *}$ &, $954^{* * *}$ &, $998^{* *}$ &, $992^{* *}$ &, $970^{* *}$ & 1,000 & & & & & & \\
\hline Millousi & ,998** &, $985^{* *}$ &, $895^{* *}$ &, $988^{* *}$ &, $993^{* * *}$ &, $962^{* *}$ &, $985^{* *}$ & ,998** &, $969^{* *}$ & 1,000 & & & & & \\
\hline Delladio &, $973^{* * *}$ &, $984^{* *}$ &, $880^{* *}$ &, $977^{* *}$ &, $982^{* * *}$ &, $972^{* *}$ &, $989^{* *}$ &, $985^{* *}$, &, $979^{* *}$ &, $982^{* *}$ & 1,000 & & & & \\
\hline Tijmes &, $993^{* * *}$ &, $989^{* * *}$ &, $892^{* *}$ &, $986^{* *}$ &, $993^{* * *}$ &, $966^{* *}$ &, $986^{* *}$ &, $998^{* *}$, &, $973^{* *}$ &, $998^{* *}$ &, $990^{* * *}$ & 1,000 & & & \\
\hline Golob &, $961^{* *}$ &, $967^{* *}$ &, $984^{* *}$ &, $903^{* *}$ &, $972^{* *}$ &, $855^{* *}$ &, $911^{* *}$ &, $946^{* *}$, &, $869^{* *}$ &, $949^{* *}$ &, $936^{* *}$ &, $946^{* *}$ & 1,000 & & \\
\hline Urvikko 1 &, $981^{* * *}$ &, $977^{* *}$ &, $971^{* *}$ &, $936^{* *}$ & $987^{* * *}$ &, $892^{* *}$ &, $940^{* *}$ & $968^{* * *}$, &, $905^{* *}$ &, $972^{* * *}$ &, $954^{* *}$ &, $968^{* * *}$ &, $996^{* *}$ & 1,000 & \\
\hline Urvikko 2 &, $989^{* * *}$ &, $983^{* *}$ &, $962^{* *}$ &, $947^{* *}$ &, $992^{* * *}$ & $906^{* *}$ &, $949^{* * *}$ &, $978^{* *}$, &, $919^{* *}$ &, $982^{* *}$ &, $962^{* * *}$ &, $979^{* * k}$ & $990^{* * *}$, & ,998 & 1,000 \\
\hline $\begin{array}{r}\text { Significanc } \\
\text { KOVT, I } \\
\text { KOVT, }\end{array}$ & $\begin{array}{l}e^{* *} \cdot p \leq \\
\text { Paulicko } \\
\text { Roberts } \\
\text { KOVT }\end{array}$ & $\begin{array}{l}\text { S.01. } \\
\text { ova (SV } \\
\text { (GBR)- } \\
\text { T, Golob }\end{array}$ & $\begin{array}{l}\text { Female } \\
\mathrm{JK})-1^{\mathrm{st}} \\
-1^{\text {st }} \mathrm{KO} \\
\mathrm{b} \text { (SLO) }\end{array}$ & $\begin{array}{l}\text { gymnas } \\
{ }^{\text {KOVVT }} \\
\text { OVT, M } \\
\text { ) }-1^{\text {st }} \mathrm{K}\end{array}$ & $\begin{array}{l}\text { sts: May } \\
\text { Г, Han } 1 \\
\text { Tillousi ( } \\
\text { OVVT, U }\end{array}$ & $\begin{array}{l}\text { yer (AU } \\
1 \text { (CHN } \\
\text { (GRE) - } \\
\text { Urvikko }\end{array}$ & $\begin{array}{l}\text { JT) }-1^{\text {st }} \\
\text { J) }-1^{1 \mathrm{tt}} \mathrm{KC} \\
-1^{\text {st }} \mathrm{KO} \\
1 \text { (FIN) }\end{array}$ & $\begin{array}{l}\text { KOVT, } \\
\text { OVT, H } \\
\text { OVT, De } \\
-1^{\text {st }} \mathrm{KO}\end{array}$ & $\begin{array}{l}\text { Erceg } \\
\text { Han } 2 \text { (C } \\
\text { elladio } \\
\text { OVT, U }\end{array}$ & $\begin{array}{l}\text { (CRO) } \\
\text { (CHN) } \\
\text { (CRO) } \\
\text { Urvikko }\end{array}$ & $\begin{array}{l}-1^{\mathrm{st}} \mathrm{KC} \\
-2^{\text {nd }} \mathrm{KO} \\
-1^{\mathrm{st}} \mathrm{KO} \\
2 \text { (FIN) }\end{array}$ & $\begin{array}{l}\text { OVT, G } \\
\text { OVT, B } \\
\text { OVT, Ti } \\
\text { I) }-2^{\text {nd }} \mathrm{K}\end{array}$ & $\begin{array}{l}\text { Sombas } \\
\text { riand (F } \\
\text { ijmes ( }\end{array}$ & $\begin{array}{l}\text { s (HUN } \\
\text { (FRA) - } \\
\text { (NED) }\end{array}$ & $\begin{array}{l}-1^{\mathrm{st}} \\
1^{\mathrm{st}} \\
-1^{\mathrm{st}}\end{array}$ \\
\hline
\end{tabular}

High values of the trajectory of the foot along the y-axis $(.778-.998)$ were obtained for the intercorrelation of the kinematic parameters (Table 1). Their intercorrelation is large, the significance level is 0.01 and with a $1 \%$ risk factor the connection between the trajectories of the foot between the gymnasts who performed the Clear hip Circle to Handstand along the y-axis.

Table 2 presents the movement speed of the foot along the y-axis of the gymnasts who performed the clear hip circle to Handstand on the uneven bars at the $39^{\text {th }}$ and $40^{\text {th }}$ Word Cup in Maribor (SLO).

Table 2 presented the optimal values for movement speed in the xy-axis (.514- .994). Their intercorrelation is range, from an average to large correlation. The significance level is 0.01 and it can be interpreted with a $1 \%$ risk factor of connection of the movement speed between the gymnasts who performed the Clear hip Circle to Handstand in the xy-plane.

An analysis of whether the limits of the final score of every female gymnast from the competition are competitive on the UB cannot be done without determining the most important position in the successful performance of KOVT techniques. The final score that was been given to the female gymnasts were: Mayer (12.100), Erceg (13.500), Gombas (12.200), Pechancova (12.750), Paulickova (11.050), Han (14.300), Briand (12.500), Roberts (12.650), Millousi (13.050), Delladio (12.600), Tijmes (12.300), Golob (10.350), Urvikko (11.350). Based on Figure 7 and expert assessment we determined the most important positions in the technique KOVT. In the first phase, the most important positions are the $21^{\text {st }}$ and $28^{\text {th }}$, because they are the positions where the trajectories of the 
studied points intersect. Positions 21 and 28 are interesting as they represent the position in which the range of the examined parameters are the greatest. Position 29 has been chosen to determine the significance of any differences, the same as position 43 and 48 .

Table 2 Intercorrelation: foot speed in the xy-plane for KOVT
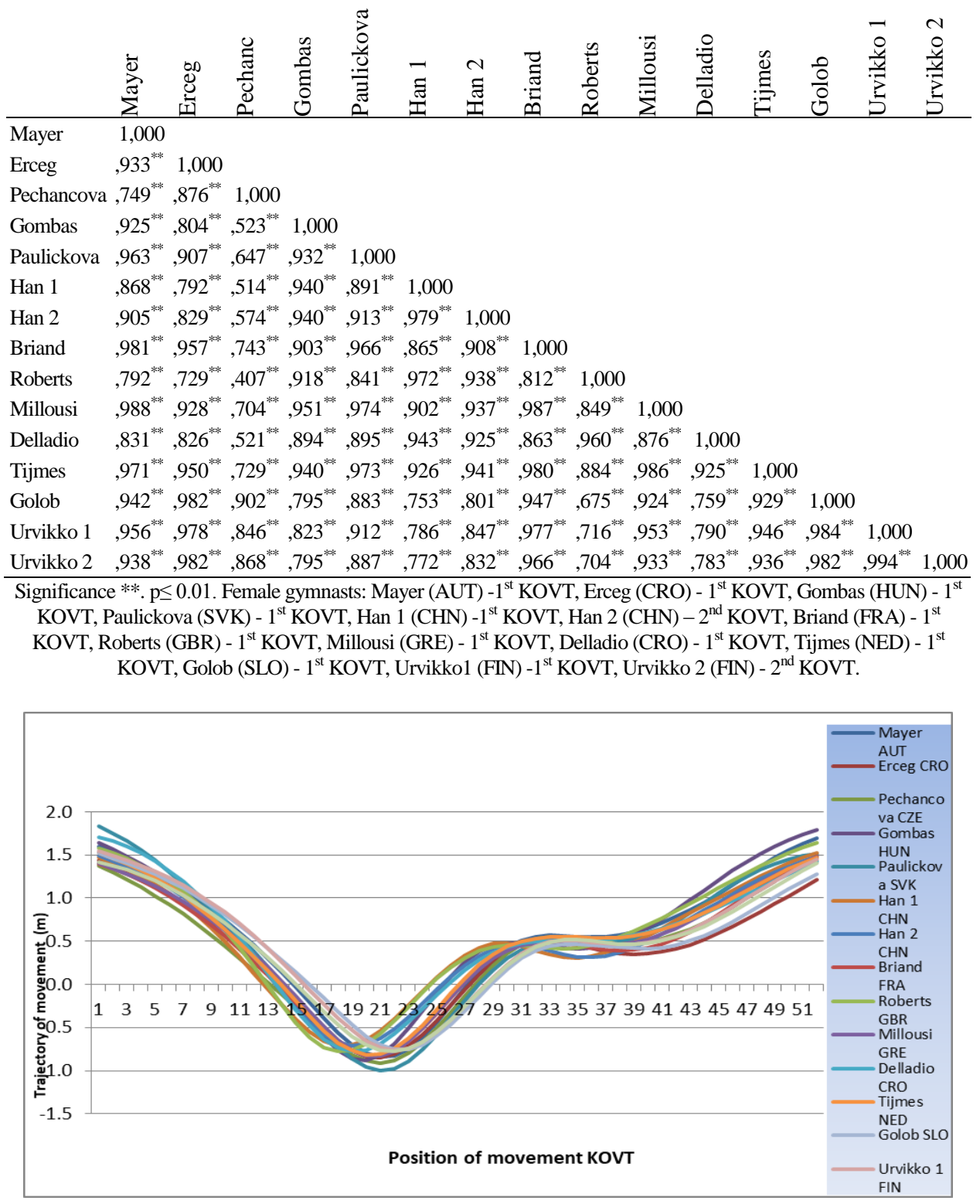

Fig. 7 Graph of the trajectory of the y-axis of foot movement trajectory 
Tables 3-6 have shown the influence of the examined parameters on the final score. These tables presented the results of the multivariate regression analysis. We used a multivariate regression analysis to determine the significance of the influence of the relevant kinematic parameters and the final grades of the gymnastics.

Table 3 Regression analysis of the ankle joint in the final score of the female gymnasts

\begin{tabular}{ccccccc}
\hline Position & $\mathrm{r}$ & Part-r & $\mathrm{b}$ & Std.Err. - of $\mathrm{b}$ & $\mathrm{t}(9)$ & $\mathrm{p}$-value \\
\hline 21 & 0.31 & -0.042 & -0.5005 & 3.98795 & -0.125510 & 0.902879 \\
28 & 0.52 & 0.323 & 19.4792 & 19.00001 & 1.025221 & 0.332024 \\
29 & 0.48 & -0.257 & -16.9016 & 21.19925 & -0.797273 & 0.445816 \\
43 & 0.20 & 0.057 & 1.7002 & 9.92603 & 0.171290 & 0.867785 \\
48 & 0.14 & -0.200 & -4.9433 & 8.07349 & -0.612293 & 0.555496 \\
$\mathrm{R}=0.703$ & \multicolumn{7}{c}{$\mathrm{R}=0.494$} & $\mathrm{~F}(5,9)=1.7608$ & $\mathrm{p}<0.21706$ \\
\hline Significance $* * \mathrm{p} \leq 0.01$; The coefficient of determination $-\mathrm{R}^{2} ;$ The coefficient of multiple correlation $-\mathrm{R}$
\end{tabular}

Table 4 Regression analysis of the foot in the final score of the female gymnasts

\begin{tabular}{ccccccc}
\hline Position & $\mathrm{r}$ & Part-r & $\mathrm{b}$ & Std.Err. - of b & $\mathrm{t}(9)$ & $\mathrm{p}$-value \\
\hline 21 & 0.44 & -0.089 & -1.1209 & 4.20414 & -0.266615 & 0.795774 \\
28 & 0.49 & 0.285 & 17.3503 & 19.44030 & 0.892492 & 0.395365 \\
29 & 0.46 & -0.231 & -15.7107 & 22.00916 & -0.713824 & 0.493431 \\
43 & 0.16 & 0.128 & 3.2739 & 8.45436 & 0.387247 & 0.707572 \\
48 & 0.08 & -0.275 & -5.6740 & 6.61279 & -0.858030 & 0.413142 \\
$\mathrm{R}=0.715$ & \multicolumn{2}{c}{$\mathrm{R}^{2}=0.511$} & $\mathrm{~F}(5,9)=1.8799$ & $\mathrm{p}<0.19353$ \\
\hline Significance ** $\mathrm{p} \leq 0.01 ;$ The coefficient of determination $-\mathrm{R}^{2} ;$ The coefficient of multiple correlation $-\mathrm{R}$
\end{tabular}

Table 5 Regression analysis of the hip joint in the final score of the female gymnasts

\begin{tabular}{ccccccc}
\hline Position & $\mathrm{r}$ & Part-r & $\mathrm{b}$ & Std.Err. - of b & $\mathrm{t}(9)$ & $\mathrm{p}$-value \\
\hline 21 & -0.47 & -0.178 & -4.1088 & 7.58203 & -0.54192 & 0.601032 \\
28 & -0.31 & -0.365 & -41.3934 & 35.18017 & -1.17661 & 0.269532 \\
29 & -0.24 & 0.442 & 49.4804 & 33.50327 & 1.47688 & 0.173821 \\
43 & 0.35 & 0.085 & 3.4121 & 13.38029 & 0.25501 & 0.804450 \\
48 & 0.33 & -0.067 & -2.3363 & 11.64981 & -0.20054 & 0.845513 \\
$\mathrm{R}=0.650$ & \multicolumn{7}{c}{$\mathrm{R}^{2}=0.423$} & $\mathrm{~F}(5,9)=1.3186$ & $\mathrm{p}<0.33784$ \\
\hline \multicolumn{2}{l}{ Significance $* * \mathrm{p} \leq 0.01$; The coefficient of determination - $\mathrm{R}^{2} ;$ The coefficient of multiple correlation $-\mathrm{R}$}
\end{tabular}

Table 6 Regression analysis of the shoulder joint in the final score of the female gymnasts

\begin{tabular}{cccrccc}
\hline Position & $\mathrm{r}$ & \multicolumn{1}{c}{ Part-r } & \multicolumn{1}{c}{$\mathrm{b}$} & Std.Err. - of b & $\mathrm{t}(9)$ & $\mathrm{p}$-value \\
\hline 21 & -0.60 & -0.040 & -2.0550 & 17.14656 & -0.11985 & 0.907234 \\
28 & -0.43 & -0.380 & -44.4003 & 36.03180 & -1.23225 & 0.249076 \\
29 & -0.39 & 0.403 & 42.7540 & 32.39214 & 1.31989 & 0.219456 \\
43 & 0.48 & 0.087 & 2.6091 & 10.00943 & 0.26066 & 0.800218 \\
48 & 0.43 & -0.042 & -1.3560 & 10.70220 & -0.12670 & 0.901963 \\
$\mathrm{R}=0.728$ & \multicolumn{2}{c}{$\mathrm{R}^{2}=0.530$} & $\mathrm{~F}(5,9)=2.0312$ & $\mathrm{p}<0.16774$ \\
\hline
\end{tabular}

Significance ** $\mathrm{p} \leq 0.01$; The coefficient of determination $-\mathrm{R}^{2}$; The coefficient of multiple correlation $-\mathrm{R}$

The statistical analysis (Table 3-6) did not determine any significant correlation between the scores that the gymnasts received in the finals of the competitions and expert 
positions in the technique of performing the KOVT. This has a significant influence on the styles in the successful performing of this basic element. Based on the significance coefficient $p \leq 0.01$, we find that there is no statistical significance of the selected kinematic parameters in expertly assessed positions for the final score. The influence of kinematical parameters on the performance which are presented by the final score has been explained by the size of the multiple correlation. The influence ranges from 0.703 0.728 . The coefficient of determination estimates the variability of the phenomenon or the percentage contribution of the kinematics parameters to the success of the performance. The coefficient of determination ranges from $49.4 \%-53 \%$.

For a performed skill, Lees (2002) suggested that technique can be categorised into different styles, general or specific; both of which would influence the selection process. In addition to this, technique selection can be dictated by the technical requirements of a skill and the physical characteristics of the performer. Different styles of exercise technique depend on several parameters, and the most important are the body height and weight of the gymnastics and the speed-muscular properties of the technique of performance. The particularity of the style of the technique is also the specialty of the gymnastics skill.

Practical applications of this research contributed practical values of the kinematics parameters that lead to the successful execution of the technique KOVT through four phases (Fig. 13): I Control gravity phase - (1-16 position); II Gravitational phase (17-36); III Lower vertical passing (37-46); IV Swing to Handstand position (47-52). Graph $12-$ 13 have shown the trajectory of the variability of the Center of gravity of body of all female gymnasts along the $\mathrm{x}$ and $\mathrm{y}$ axis.

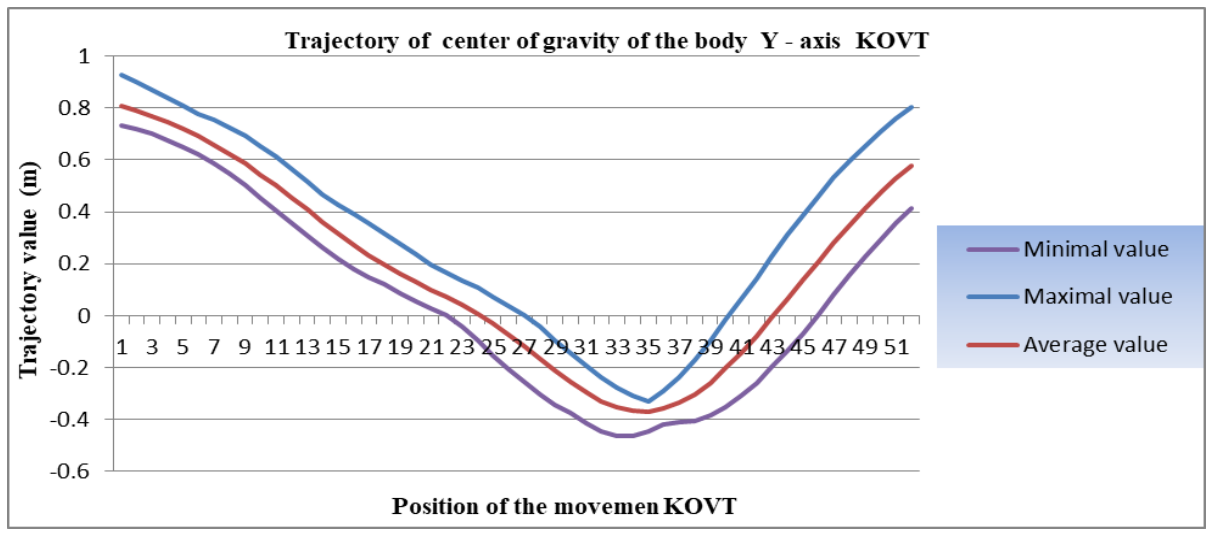

Fig. 8 Graph of the trajectory of the y-axis of center of gravity movement trajectory

The starting position of movement of the Center of gravity range in the first position has a minimal value $0.733 \mathrm{~m}$, maximal value $0.925 \mathrm{~m}$, and the average value is $0.806 \mathrm{~m}$ (Fig. 8). By the end of the first phase, in the $16^{\text {th }}$ position, the range of the values of the parameter of the Center of gravity of the gymnast's body is from $0.180 \mathrm{~m}-0.393 \mathrm{~m}$; the average value of this case study is $0.273 \mathrm{~m}$. By the end of the second phase, in the $36^{\text {th }}$ position, the range of the value of the parameter of the Center of gravity of the gymnast's body starts from $-0.288 \mathrm{~m}$ to - 
$0.418 \mathrm{~m}$; the average value for passing the $36^{\text {th }}$ position in the $-0.357 \mathrm{~m}$. At the end of the third phase, in the $46^{\text {th }}$ position minimal value $0.311 \mathrm{~m}$ to maximal value of $0.436 \mathrm{~m}$, and average $0.368 \mathrm{~m}$. By the end of the fourth phase, all values increased slightly.

Practical applications of this research contributed to the practical average values of the kinematic parameter - center of the gravity of optimized value of a female gymnast's body that lead to the successful execution of the technique KOVT through four phases. The starting position of movement of the Center of gravity ranges in the first position with an average value of $0.806 \mathrm{~m}$. In the $16^{\text {th }}$ position, when the first phase ends, an average value of this case study is $0.273 \mathrm{~m}$. By the end of the second phase, the average value of the passing $36^{\text {th }}$ position in $-0.357 \mathrm{~m}$. At the end of the third phase, in the $46^{\text {th }}$ position the average value is $0.368 \mathrm{~m}$, till the end of the movement, when all values have increased slightly.

\section{CONCLUSION}

The biomechanical analysis highlighted the characteristics of the key positions and the influence of the biomechanical indicators on the technical execution. The Clear hip circle to Handstand belongs to a group of basic movement and it is necessary to practice this technique for performing many other complex gymnastic exercises on the uneven bars. A kinematic model defined in this way as a case study will promote the process of creating a methodological training procedure which should facilitate the process of learning exercises through the analysis of individual phases. Information given in the form of a case study could optimize the performance of other young gymnasts at all levels of performance. The statistical analysis did not determine the significant correlation between the scores that the gymnasts received in the finals of competitions and expert positions in the technique of performing the KOVT. This has a significant influence on the styles in the successful performing on this basic element. This case study defines the necessary parameters of the successful implementation of the KOVT. Optimizing the technique of successful performance of the KOVT is important for detecting different styles of technique that occur in female gymnasts.

Acknowledgements: The paper is a part of the research done within the project "Biomechanical analysis of basic elements on uneven bars". The author would like to thank to the Slovenian Gymnastic Federation for their Project at the $39^{\text {th }}$ and 40th World Cup in Artistic gymnastics in Maribor (SLO).

\section{REFERENCES}

Alekperov, S.A. (1987). Upražnenia na brusjah (Persistence on the bars). Moskva: FIS. In Russian Brüggemann, G.P., Cheetham, P., Alp, Y., \& Arampatzis, D. (1994). Approach to a biomechanical profile of dismounts and release-regrasp skills of the high bar. Journal of Applied Biomechanics, 10 (3), 291-312.

George, G. (1980). Movement analysis of clear hip circle to handstand. Australian Gymnast, Coaches Supplement. Retrived on September 10, 2016 at the World Wide Web: http://www.coaches.info.com

Federation Internationale de Gymnastique - FIG Code of points for women's artistic gymnastics. 2008. Retrived on October 15, 2016 at the World Wide Web: http://www.fig-gymnastics.com

Hanin, Y., \& Hanina, M. (2009). Optimization of performance in top-level athletes: An action-focused coping approach. International Journal of Sport Science and Coaching, 4 (1), 47-91. 
Hiley, J.M. (2012). Incorporating aspects of motor control in the optimization of human performance. Science et Motricité, 75, 49-57.

Hiley, J.M., \& Yeadon, P.M. (2013). Investigating optimal technique in a noisy environment: application to the upstart on uneven bars. Human Movement Science 32, 181-191.

Kolar, E., Andlovic-Kolar, K., \& Štuhec, S. (2002). Comparative analysis of selected Biomechanic characteristics between a support backward swing and support swing for the 1-1/4 straddle - Piked forward salto on the parallel bars. Sports Biomechanics, 1(1), 69-78.

Pidcoe, P., Grehman, T., \& McPherson, D. (2010). Twisting basics II: Uneven parallel bars. Technique, 10-12, 16.

Petković, E. (2009). Optimization of the techniques of circular backward movements on uneven bars using kinematic modeling. Unpublished doctoral dissertation, Niš: Faculty of Sport and Physical Education. In Serbian

Petković, E., Veličković, S., \& Stanković, R. (2006). Optimal kinematic model of technique clear hip circle to handstand on the uneven bars. In D. Zivković (Ed.), 12 National Scientific Conference with International Participation FIS Communications 2006, (pp. 135-143), Niš: Faculty of Sport and Physical Education. In Serbian

Popov, D. (1986). Comparison of kinematic motion of classical and contemporary upswing performing back giant circle on rings. Fizička kultura, 86 (3), 328-331. In Serbian

Potop, V., Timnea, O.C., Costinel, M., \& Carmen, M. (2014). Biomechanical characteristics of back double salto dismount off the uneven bars. Journal of Physical Education and Sport, 14(2), 248-253.

Prassas, S. (1994). Technique analysis of the back toss on the parallel bars performed by elite gymnasts. In A. Barabas \& G. Fabian (Eds.), Biomechanics in Sports XII (pp. 249-251). Budapest, Hungary: ISBS.

Prassas, S. (2002). What is done, what is needed? Biomechanical research in gymnastics, Colorado State University, USA, Retrieved May 25, 2006 at the World Wide Web: http:// www.education.ed.ac.uk/gym/papers/sp.html

Takei, Y., \& Dunn, J.H. (1996). A comparison of techniques used by elite gymnasts in performing the basketto-handstand mounts. Journal of Sports Sciences, 14, 269-279.

Tsuchiya, J., Murata, K., \& Fukunaga, T. (2004). Kinetic analysis of backward giant swing on parallel bars. International Journal of Sport and Health Science, 2 (1), 211-221.

Lees, A. (2002). Technique analysis in sports: a critical review. Journal of Sports Sciences, 20, 813-828.

Suchilin N.G. (2010). Gymnastics: Theory and practice: Methodical approach to the journal "Gymnastics" of Russian Federation of Artistic Gymnastics. Moscow: Soviet Sport, 5-13.

Veličković, S. (2005). Defining kinematic model techniques of performing the most complex gymnastic exercises. Unpublished doctoral dissertation, Novi Sad: Faculty of Sport and Physical Education. In Serbian

Veličković, S., Kugovnik, O., Kolar, E., Bubanj, R., Madić, D., \& Supej, M. (2005). Primerjava nekaterih kinematičnih spremenljivk med točem in točem $\mathrm{z}$ obratom na bradlji (Comparison of some kinematic variables between turn and turn on the bars). Šport, letnik 50 (1), 1, 63-69. In Slovenian

Veličković, S., Kugovnik, O., Kolar, E., Madić, D., \& Piletič, S. (2006). Predlog metode definiranja kinematičnega modela tehnike izvedbe kompleksnih gimnastičnih prvin (Proposal of the method for defining the kinematic model of the performing technique of complex gymnastic elements). Gimnastika za trenerje in pedagoge, 2, 30-38. In Slovenian

Veličković, S., Kolar, E., Kugovnik, O., Petković, D., Petković, E., Bubanj, S., Bubanj, R., \& Stanković, R. (2011). The kinematic modela of the basket to handstand on the parallel bars. Facta Universitatis Series Physical Education and Sport, 9 (1), 55-68

Veličković, S., Kolar, E., \& Petković, D. (2006). The kinematic model of the basket with $1 / 2$ turn to handstand on the parallel bars. Facta Universitatis Series Physical Education and Sport, 4, (2), 137-152.

Winter, A.D. (1991). Biomechanics and motor control of human movement, Second Edition. John Wiley \& Sons, Inc. New York 


\section{OPTIMALNI KINEMATIČKI MODEL IZVOĐENJA KOVRTLJAJA NAZAD DO STAVA U UPORU NA DVOVISINSKOM RAZBOJU - STUDIJA SLUČAJA}

Cilj ovog istraživanja bio je da se definiše optimalni kinematički parametri izvođenja vežbe Kovrtljaj nazad do stava u uporu na Dvovisinskom razboju (KOVT). Vežba je izvedenana 39. i 40. Svetskom prvenstvu u Sportskoj gimnastici u Mariboru (SLO). Kinematički parametri određeni su $3 D$ video sistemom APAS, koristeći 16 antropometrijskih tačaka i 8 delova tela (tačke stopala, skočnog zgloba, zgloba kolena, kuka, lakta, ramena i temena glave) u kojima jedna od tačaka predstavlja centar gravitacije tela. Gimnastičarke $(N=15)$ prosečne starosti, 17.5 godina koje su izvele jedan Kovrtljaj do stoja izvele su dva puta Kovrtljaj do stoja u svojim sastavima, dok su ostale gimnastičarke izvele jedan Kovrtljaj do stoja na Dvovisinskom razboju,. Glavna metoda u ovom istraživanju bila je kinematička, a dodatna je bila statistička. Optimalizacija tehnike uspešnog izvođenja KOVT bitna je zbog uočavanja različitih stilova tehnike koji se javljaju kod gimnastičarki.

Ključne reči: gimnastičarke, kinematika, Dvovisinski razboj, analiza tehnike 